\title{
Sikojen terveydenhuoltorekisterin Sikavan tuloksia 2014
}

\author{
Nikunen Sanna, Kortesniemi Pirjo \\ Eläinten terveys ETT ry \\ PL 221 \\ 60101 Seinäjoki \\ s-posti: etunimi.sukunimi@ett.fi
}

\section{Tiivistelmä}

Sikava on vapaaehtoinen Eläinten terveys ETT ry:n ylläpitämä ja nettiselaimella toimiva sikojen terveydenhuollon rekisteri, joka valmistui v. 2003 ETT:n ja Sikavan jäsenteurastamoiden yhteistyöllä. Sikavan avulla sikatilat luokitellaan rekisteriin kertyneen terveydenhuollon tietojen perusteella kansalliselle tai perustasolle. Sikavan jäsenteurastamot hyödyntävät Sikavan luokitustietoa oman tuotantoketjun ohjauksessa ja kuljetuslogistiikassa. Kansalliselle tasolle luokiteltu sikala noudattaa kansallista terveydenhuolto-ohjelmaa ja ylittää lainsäädännön vaatimukset mm. sikojen terveyden ja elintarviketurvallisuuden suhteen. Sikavan laatujärjestelmälle myönnettiin 2014 ISO 9001 laatusertifikaatti. Tässä abstraktissa kuvaillaan kansallisen terveydenhuolto-ohjelman tuottamaa tietoa vuodelta 2014.

Terveydenhuolto-ohjelmaan kuuluu säännölliset dokumentoidut terveydenhuoltokäynnit 3-6 kertaa vuodessa. Eläinlääkäri havainnoi tilakäynnillä eläinten sairastavuutta ja hyvinvointia, eri tautien esiintymistä tilalla ja olosuhteita mm. karsinoiden puhtautta, eläintiheyttä ja virikemateriaalin määrää eri ikäryhmissä. Eläinten sairastavuutta arvioidaan oireiden määrällä; merkitään ei oireita $(0 \%)$ tai oireita esiintyy muutamalla (1-5\%), usealla (6-19\%) tai paljon (>20\%). Kuolleisuusprosentit otetaan lomakkeeseen eläinryhmittäin. Hyvinvointia tarkastellaan em. lisäksi kuntoluokitusten (asteikko 1-5) sekä emakoiden lapavaurioiden kautta (asteikko ei vaurioita, lievä vaurio, vakava vaurio). Olosuhteet arvioidaan asteikolla; hyvä, tyydyttävä tai heikko. Eläintautien esiintyminen arvioidaan asteikolla; ei todettu, epäily tai todettu.

Vuoden 2014 aikana Sikavaan kirjattiin 6285 terveydenhuoltokäyntiä 1418 eri pitopaikalle. Havaintoja kirjattiin porsastuotantotiloilta 158, lihasikaloissa 60 havaintokohdasta. Esimerkiksi ilman laatu todettiin lihasikaloissa hyväksi $86,5 \%$ käynneistä. Sairauden oireista esimerkiksi ripuli oli harvinainen havainto suomalaisessa lihasikalassa, ripulia todettiin 8,5\% käynneistä. Hännänpurenta oli lihasikaloissa ongelmana 2,4\% tilakäyntihavainnoista. Lapavaurioita emakoilla ei todettu $89 \%$ havainnoista. Kuolleisuus oli lihasioilla keskimäärin 2,9\% ja emakoilla 8,0 \%. Niistä taudeista, joista kansallisen tason tilan tulee olla vapaa, todettiin kapia yhdellä tilalla ja sikadysenteriaa neljällä tilalla. Porsasyskää, aivastustautia eikä salmonellaa todettu lainkaan.

Vuoden 2014 tulokset osoittavat, että Suomessa sikasektorilla terveydenhuoltotyö on systemaattista ja hyvin dokumentoitua. Sikojen terveystilanne on hyvä, tuotantosairaudet ja tarttuvat taudit ovat hyvin hallinnassa. Eläinten hyvinvointi on sioista havainnoitavilla indikaattoreilla hyvällä tasolla. Sikavan avulla on kehitetty ja yhtenäistetty terveydenhuoltoa, kerätty tietoa, edistetty sikojen hyvinvointia, erityisesti terveyttä ja parannettu elintarviketurvallisuutta.

\section{Asiasanat:}

sika, sikatila, terveydenhuolto, terveydenhuolto-ohjelma, Sikava, tilakäynti, ripuli, hännänpurenta, lapavaurio, kapi, sikadysenteria, porsasyskä, aivastustauti, salmonella 


\section{Johdanto}

Sikava on vapaaehtoinen Eläinten terveys ETT ry:n ylläpitämä ja nettiselaimella toimiva sikojen terveydenhuollon rekisteri, joka valmistui v. 2003 ETT:n ja Sikavan jäsenteurastamoiden yhteistyöllä. Se perustettiin toteuttamaan ja kehittämään sikatilojen terveydenhuoltoa. Sikavan ensisijaisena tehtävänä on edistää kansallisen tason toteutumista suomalaisilla sikatiloilla sekä valvoa, kehittää ja ylläpitää tietokantaa kansallisen tason sikaloista. Sikavan avulla sikatilat luokitellaan rekisteriin kertyneen terveydenhuollon tietojen perusteella erityis-, kansalliselle- tai perustasolle. Sikavan jäsenteurastamot hyödyntävät Sikavan luokitustietoa oman tuotantoketjun ohjauksessa ja kuljetuslogistiikassa.

Sikaloiden terveysluokituksen perusteena ovat ETU-sika-asiantuntijaryhmässä yhteisesti sovitut, lainsäädännön yli menevät terveydenhuollon toimet, joista elintarvikeketjun kaikki osapuolet hyötyvät. Näitä toimenpiteitä ovat $\mathrm{mm}$. terveydenhuoltosopimus eläinlääkärin ja tilan välillä, säännölliset eläinlääkärin tekemät ja dokumentoimat terveydenhuoltokäynnit, terveydenhuoltosuunnitelma, tautivapauksien todentaminen tutkimuksin, eläinten terveyden, hyvinvoinnin ja tuotanto-olosuhteiden seuranta sekä tilan tautisuojaustoimien toteutus. Kansalliselle tasolle luokiteltu sikala noudattaa kansallista terveydenhuolto-ohjelmaa ja ylittää lainsäädännön vaatimukset mm. sikojen terveyden ja elintarviketurvallisuuden suhteen.

Sikavalla on ollut oma laatujärjestelmä vuodesta 2013 alkaen. Järjestelmälle on annettu Eviran myöntämä kansallisen laatujärjestelmän status 2013 ja ISO 9001 laatusertifikaatti 2014 (Bureau Veritas).

Sikava toimii internetissä osoitteessa www.sikava.fi. Se on henkilörekisterilain alainen rekisteri. Tässä esityksessä kerrotaan tarkemmin kansallisen terveydenhuolto-ohjelman tuottamasta tiedosta vuodelta 2014.

\section{Aineisto ja menetelmät}

Terveydenhuolto-ohjelmaan kuuluvat eläinlääkärin 3-6 kertaa vuodessa tekemät dokumentoidut terveydenhuoltokäynnit. Terveydenhuoltokäynneillä eläinlääkäri kirjaa havainnot Sikavan käyntilomakkeeseen ja tallentaa lomakkeen rekisteriin. Nykyinen lomakemalli on ollut käytössä vuodesta 2011 lähtien. Porsastuotanto- ja yhdistelmätiloilla eläinlääkäri täyttää lomakkeelle 158 kohtaa, lihasikaloissa 60 kohtaa. Vuoden 2014 aikana Sikavaan kirjattiin 6285 terveydenhuoltokäyntiä 1418 eri pitopaikalle.

Eläinlääkäri havainnoi tilakäynnillä eläinten sairastavuutta ja hyvinvointia, eri tautien esiintymistä tilalla ja olosuhteita mm. karsinoiden puhtautta, rakenteiden kuntoa, eläintiheyttä ja virikemateriaalin määrää eri ikäryhmissä. Arvioi tehdään erikseen sikalan eri eläinryhmille. Olosuhteet arvioidaan asteikolla; hyvä, tyydyttävä tai heikko. Eläintautien esiintyminen arvioidaan asteikolla ei todettu, epäily tai todettu. Kansallisen tason sikalan tulee olla vapaa sioilla maailmalla yleisesti esiintyvistä tarttuvista taudeista. Nämä taudit ovat porsasyskä, sikadysenteria, kapi, aivastustauti ja salmonella. Eläinten sairastavuutta arvioidaan oireiden määrällä, jos oireita on yli $20 \%$ :lla eläimistä, tulee merkintä paljon ja vastaavasti 6-19\%:lla antaa arvion useita, 1-5\% arvion muutama ja jos oireita ei ole, merkitään ei oireita. Tilan kuolleisuusprosentit otetaan lomakkeeseen eläinryhmittäin. Hyvinvointia tarkastellaan edellä mainittujen lisäksi kuntoluokitusten (asteikko 1-5) sekä emakoiden lapavaurioiden kautta (asteikko ei vaurioita, lievä vaurio, vakava vaurio).

\section{Tulokset}

Kansallisen tason edellytyksenä olevista taudeista todettiin kapia yhdellä tilalla ja sikadysenteriaa neljällä tilalla. Porsasyskää, aivastustautia eikä salmonellaa todettu lainkaan.

Sikalan olosuhteita tarkasteltaessa esimerkiksi ilman laadusta "hyvä" merkintää oli eniten porsitusosastoissa, 91,3\%:1la ja vähiten lihasikaloissa, joissa saman arvion sai 86,5\% käynneistä (taulukko 1). Sama järjestys säilyi myös rakenteiden kuntoa tarkasteltaessa (taulukko 2) mutta virikemateriaalin määrässä "hyvä" merkintöjä tuli eniten vieroitusosastoissa, $81,4 \%$ ja toiseksi eniten lihasikaosastoissa, 77,8\%. Vähiten "hyvä" merkintöjä tuli pesäntekomateriaalista porsivilla emakoilla, $74,7 \%$ (taulukko 3).

Sairauden oireista esimerkiksi yskää ei todettu lainkaan 92\%:lla tilakäynneistä vieroitusosastoissa eikä lihasikaosastoissa. Alle 1\%:lla tilakäynneistä oli yskän oireita yli 6\%:lla 
eläimistä (taulukko 4). Suolistotulehdusta esiintyy eniten vieroitetuilla porsailla, 52,9 \% tilakäynneistä oli todettu oireita vähintään muutamalla yksilöllä, kun taas lihasikalassa ripulia todettiin vain 8,5\% käynneistä (taulukko 5). Taudinaiheuttajista oli eniten todettu Lawsonia intracellularis-bakteeria, joka aiheuttaa eniten ongelmia vieroitetuilla porsailla ja toiseksi eniten E. coli- bakteeria, joka on yleisesti esiintyvä suolistotulehdusten aiheuttaja (taulukko 6).

Eläinten hyvinvointia tarkastellaan lomakkeilla seuraamalla hännänpurennan määrää sekä emakoiden lapavaurioita ja kuntoluokkaa että tarkastelemalla sikalan eri eläinryhmien kuolleisuutta. Hännänpurentaa ei esiintynyt ollenkaan 62,1\%:lla vieroitusosastoista ja 37,7\% lihasikaloista mutta suurimmassa osassa sikaloista tapaukset olivat vain yksittäisiä (vieroitusosastoilla $36,6 \%$ merkinnöistä, lihasioilla $60 \%$ merkinnöistä)(taulukko 7). Lapavaurioiden laskennassa käytetään Welfare Qualityn ${ }^{\circledR}$ ohjeistusta lapavaurioiden arvostelussa. Lapavaurioita emakoilla ei todettu 89\% havainnoista, lievä vaurio todettiin $10 \%$ ja vakava vaurio $1 \%$. Laskennassa oli emakoita yhteensä 45283 kpl (Suomen emakkomäärä 2013125000 kpl) (taulukko 8). Eläinlääkärit kirjaavat tilan kirjanpidosta eläinten kuolleisuuden lomakkeille. Kuolleisuus oli lihasioilla keskimäärin 2,9\% ja emakoilla $8,0 \%$.

Tarkempia yksittäisiä tietoja esitetään alla olevissa taulukoissa.

Taulukko 1.

Eläinlääkäreiden tekemät merkinnät osastojen ilmanlaadusta

\begin{tabular}{|l|l|l|l|l|l|l|}
\hline & Porsitusosastot & \multicolumn{2}{l|}{ Välikasvatusosastot } & \multicolumn{2}{l|}{ Lihasikaosastot } \\
\hline & Kpl & $\%$ & Kpl & $\%$ & Kpl & $\%$ \\
\hline Hyvä & 3140 & 91,3 & 2978 & 87,1 & 4973 & 86,5 \\
\hline Tyydyttävä & 301 & 8,7 & 434 & 12,7 & 764 & 13,3 \\
\hline Heikko & 0 & 0 & 6 & 0,2 & 12 & 0,2 \\
\hline
\end{tabular}

Taulukko 2.

\begin{tabular}{|l|l|l|l|l|l|l|}
\hline Eläinlääkäreiden tekemät merkinnät osastojen rakenteiden kunnosta \\
\hline & Porsitusosastot & \multicolumn{2}{l|}{ Välikasvatusosastot } & \multicolumn{2}{l|}{ Lihasikaosastot } \\
\hline & Kpl & $\%$ & Kpl & $\%$ & Kpl & $\%$ \\
\hline Hyvä & 3016 & 87,7 & 2847 & 83,4 & 4687 & 81,6 \\
\hline Tyydyttävä & 414 & 12,0 & 559 & 16,4 & 1023 & 17,8 \\
\hline Heikko & 10 & 0,3 & 9 & 0,3 & 12 & 0,2 \\
\hline
\end{tabular}

Taulukko 3 .

Eläinlääkäreiden tekemät merkinnät osastojen virikemateriaalin määrästä

\begin{tabular}{|l|l|l|l|l|l|l|}
\hline & Pesäntekomateriaali emakoilla & Vieroitetut porsaat & \multicolumn{2}{l|}{ Lihasiat } \\
\hline & Kpl & $\%$ & Kpl & $\%$ & Kpl & $\%$ \\
\hline Hyvä & 2494 & 74,7 & 2771 & 81,4 & 4453 & 77,8 \\
\hline Tyydyttävä & 747 & 22,4 & 609 & 17,9 & 1229 & 21,5 \\
\hline Heikko & 96 & 2,9 & 25 & 0,2 & 42 & 0,7 \\
\hline
\end{tabular}

Taulukko 4.

\begin{tabular}{|l|l|l|l|l|l|l|}
\hline Eläinlääkäreiden tekemät merkinnät yskästä sairausoireena \\
\hline & Imettävät emakot & Vieroitetut porsaat & \multicolumn{2}{l|}{ Lihasiat } \\
\hline & Kpl & $\%$ & Kpl & $\%$ & Kpl & $\%$ \\
\hline Ei (0\%) & 3331 & 99,3 & 3080 & 91,9 & 5163 & 91,6 \\
\hline Muutama (1-5\%) & 24 & 0,72 & 248 & 7,4 & 433 & 7,68 \\
\hline Useita (6-19\%) & 0 & 0 & 19 & 0,6 & 28 & 0,5 \\
\hline Paljon (>20\%) & 0 & 0 & 3 & 0,1 & 11 & 0,2 \\
\hline
\end{tabular}

Taulukko 5 . 
Eläinlääkäreiden tekemät merkinnät ripulista sairausoireena

\begin{tabular}{|l|l|l|l|l|l|l|}
\hline & Imevät porsaat & \multicolumn{2}{l|}{ Vieroitetut porsaat } & \multicolumn{2}{l|}{ Lihasiat } \\
\hline & Kpl & $\%$ & Kpl & $\%$ & Kpl & $\%$ \\
\hline Ei (0\%) & 1903 & 57,5 & 1581 & 47,2 & 5120 & 91,5 \\
\hline Muutama (1-5\%) & 1331 & 40,2 & 1584 & 47,3 & 467 & 8,3 \\
\hline Useita (6-19\%) & 69 & 2,1 & 178 & 5,3 & 10 & 0,2 \\
\hline Paljon (>20\%) & 6 & 0,2 & 9 & 0,3 & 0 & 0 \\
\hline
\end{tabular}

Taulukko 6.

\begin{tabular}{|c|c|c|c|c|c|c|c|}
\hline \multicolumn{8}{|c|}{ Ruuansulatuskanavan sairauksien esiintyvyys Sikavan tilakäynneillä 2014} \\
\hline & $\begin{array}{l}\text { Clostridium } \\
\text { perfringens } \\
\text { tyyppi C } \\
(\mathrm{kpl} / \%)\end{array}$ & $\begin{array}{l}\text { Clostridium } \\
\text { perfringens } \\
\text { tyyppi A } \\
(\mathrm{kpl} / \%)\end{array}$ & $\begin{array}{l}\text { Muut } \\
\text { brachyspirat } \\
(\mathrm{kpl} / \%)\end{array}$ & $\begin{array}{l}\text { Kokkidioosi } \\
(\mathrm{kpl} / \%)\end{array}$ & $\begin{array}{l}\text { Lawsonia } \\
\text { intracellularis } \\
(\mathrm{kpl} / \%)\end{array}$ & $\begin{array}{l}\text { Rotavirus } \\
(\mathrm{kpl} / \%)\end{array}$ & $\begin{array}{l}\text { E. coli - } \\
\text { ripuli } \\
(\mathrm{kpl} \quad / \\
\%)\end{array}$ \\
\hline $\mathrm{Ei}$ & $\begin{array}{l}3541 \\
99,86\end{array}$ & $3399 / 95,9$ & $5860 / 95,3$ & $3031 / 85,4$ & $5447 / 88,8$ & $\begin{array}{ll}3451 \quad / \\
97,6\end{array}$ & $\begin{array}{l}5427 \quad / \\
88,2\end{array}$ \\
\hline Epäily & $1 / 0,03$ & $41 / 1,16$ & $228 / 3,7$ & $450 / 12,7$ & $512 / 8,4$ & $61 / 1,7$ & $\begin{array}{ll}617 \\
10,0\end{array}$ \\
\hline Todettu & $4 / 0,11$ & $106 / 2,99$ & $64 / 1,0$ & $70 / 2,0$ & $176 / 2,9$ & $25 / 0,7$ & $\begin{array}{l}108 \quad / \\
1,8\end{array}$ \\
\hline
\end{tabular}

Muut brachypirat = ei sisällä Brachyspira hyodysenteriaa

Taulukko 7.

\begin{tabular}{|l|l|l|l|l|}
\hline Eläinlääkäreiden tekemät merkinnät hännänpurennasta \\
\hline & Vieroitetut porsaat & Lihasiat \\
\hline & Kpl & $\%$ & Kpl & $\%$ \\
\hline Ei (0\%) & 2099 & 62,1 & 2158 & 37,7 \\
\hline Muutama (1-5\%) & 1238 & 36,6 & 3436 & 60,0 \\
\hline Useita (6-19\%) & 41 & 1,2 & 132 & 2,3 \\
\hline Paljon (>20\%) & 4 & 0,1 & 5 & 0,1 \\
\hline
\end{tabular}

Taulukko 8

Eläinlääkäreiden tarkastamat emakot lapavaurioiden varalta

\begin{tabular}{|l|l|l|l|}
\hline & Ei lapavaurioita & Lievä lapavaurio & Vakava lapavaurio \\
\hline Kappaletta & 40307 & 4366 & 610 \\
\hline Prosenttiosuus & 89 & 10 & 1 \\
\hline
\end{tabular}

\section{Johtopäätökset}

Vuoden 2014 tulokset osoittavat, että Suomessa sikasektorilla terveydenhuoltotyö on systemaattista ja hyvin dokumentoitua. Sikojen terveystilanne on hyvä ja eläimillä esiintyy pääasiassa ns. tuotantosairauksia. Tarttuvat taudit ovat Suomessa joko hävitetty tai hyvin hallinnassa. Eläinten hyvinvointia seurataan useilla sioista havainnoitavilla indikaattoreilla olosuhdetekijöiden lisäksi ja eläinten hyvinvointi on suomalaisissa sikaloissa hyvällä tasolla. Sikavan avulla on kehitetty ja yhtenäistetty terveydenhuoltoa keräämällä tietoa ja käyttämällä sitä paitsi sikojen hyvinvoinnin myös terveyden parantamiseen. Samalla on parannettu myös eläimistä saatavien elintarvikkeiden turvallisuutta.

\section{Kirjallisuus:}

Tilastovakka, Kotieläintilastot 2013, www.maataloustilastot .fi, TIKE

Welfare Quality® Assessment protocol for pigs. NEN 2009 